\title{
A desivo de cianoacrilato no tratamento de afinamentos e perfurações corneais: técnica e resultados
}

Cyanoacrylate tissue adhesive in cases with corneal thinning and perforation

\author{
Sérgio Felberg ${ }^{1}$ \\ Jonathan Clive Lake \\ Fabiana Amorim de Lima ${ }^{1}$ \\ Denise Atique ${ }^{1}$ \\ Sandra Cayres Naufal ${ }^{2}$ \\ Paulo Elias Corrêa Dantas ${ }^{2}$ \\ Maria Cristina Nishiwaki-Dantas ${ }^{3}$
}

\section{RE S U MO}

Objetivos: Relatara experiência obtida comouso de adesivo de cianoacrilato em 22 casos seriados, e não comparativos, de afinamentos ou perfurações corneais de etiologia variada. Também visa descrever a técnica proposta para a aplicação do adesivo. Métodos: Foram estudados 22 olhos de 22 pacientes que apresentavam afinamentos ou perfurações corneais, tratados com adesivo de cianoacrilato (Super Bonder ${ }^{\circledR}$ - Loctite, Brasil), no Departamento de Oftalmologia da Santa Casa de São Paulo, entre outubro de 1998 e abril de 2000. Os parâmetros avaliados foram: idade do paciente, sexo, acuidade visual antes e após aplicação do adesivo (com a correção em uso), medida (em milímetros) da perfuração ou afinamento, doença ocular que levou diretamente à necessidade da aplicação do adesivo, necessidade de "patch" ou transplante tectônico após tentativa de selar a lesão com o adesivo, número de aplicações realizadas, tempo de permanência da cola, efeitos indesejáveis após a colocação do adesivo e evolução do caso. Resultados: A acuidade visual dos pacientes mantevese inalterada após a aplicação da cola em 15 casos (68\%). Com relação ao tamanho das lesões, a maioria pertence ao grupo que variou entre 1 e 2 milímetros $(63 \%)$. As infecções constituíram a mais freqüente indicação para o uso do adesivo (50\%). Doze pacientes (54\%) não necessitaram transplante ou "patch" de córnea. Dos 22 olhos estudados, onze (50\%) necessitaram de apenas uma aplicação do adesivo. Conclusão: No presente estudo, o cianoacrilato mostrou-se seguro e de grande utilidade na manutenção da integridade ocular em casos de afinamentos e perfurações corneais.

Descritores:Cianoacrilatos/utilização;Adesivos teciduais/utilização;Transplantede cómea;Cómea/lesões

I N T ROD U Ç Ã O

Adesivos teciduais são utilizados em oftalmologia em situações especiais como afinamentos corneais importantes de etiologia variada, microperfurações corneais, perfurações corneais de difícil resolução cirúrgica (lesões "estreladas") ou no eixo visual, fístulas em ferida de ceratoplastia e outros ${ }^{(1-4)}$.

A aplicação destes adesivos visa manter a integridade ocular, principalmente isolando o conteúdo intra-ocular do meio extra-ocular, prevenindo desta forma o desenvolvimento de endoftalmite e outras complicações como catarata, glaucoma, etc. Uma segunda intervenção pode ser realizada oportunamente com o objetivo de restabelecer a capacidade funcional, embora em alguns casos apenas a aplicação do adesivo pode ser suficiente para atingir esta finalidade, dispensando procedimentos adicionais. 
Clinicamente, são utilizados os adesivos de fibrina e os de cianoacrilato. O primeiro teve seu uso liberado pelo "Food and Drug Admnistration" (FDA) para a aplicação em humanos, mas não está disponível comercialmente no Brasil. Tem a vantagem de ser reabsorvido e substituído naturalmente por tecido fibroso, é pouco tóxico e de superfície pouco áspera e não necessita de colocação de lente de contato ${ }^{(5)}$.

O cianoacrilato quando em contato com a água, polimeriza-se e solidifica-se rapidamente, formando uma placa que serve de suporte para a cicatrização e epitelização do tecido subjacente, inibe a migração de células inflamatórias retardando a necrose tecidual e tem ação bacteriostática ${ }^{(6)}$, porém causa desconforto devido ao atrito com a pálpebra, pois sua superfície é rugosa, necessitando do uso de lente de contato com finalidade terapêutica.

O cianoacrilato deve permanecer no olho até que o processo cicatricial tenha ocorrido, podendo ocorrer seu desprendimento espontâneo ou ser efetuada sua remoção quando assim desejada (na disponibilidade de tecido biológico para a realização de "patch" ou transplante tectônico de córnea, por exemplo). Sua toxicidade é inversamente proporcional ao número de carbonos na cadeia alquil, sendo os mais tolerados os derivados isobutil, n-heptil e n-octil. A forma n-butil cianoacrilato (conhecido como Histoacryl) encontra-se comercialmente no Canadá e países da Europa. São bem tolerados no estroma corneal $^{(7-8)}$; porém, quando injetado inadvertidamente na câmara anterior podem ocasionar falência endotelial ${ }^{(9-10)}$ e em contato com a conjuntiva podem desencadear a formação de simbléfaros ${ }^{(11)}$.

Este trabalho tem como objetivo relatar a experiência obtida com o uso de cianoacrilato em 22 casos seriados e não comparados, de afinamentos ou perfurações corneais. Também visa descrever minuciosamente a técnica proposta para a aplicação do adesivo.

MÉ T OD O S

Foram estudados 22 olhos de 22 pacientes que apresentavam afinamentos ou perfurações corneais, tratados com adesivo de etil-cianoacrilato (Super Bonder ${ }^{\circledR}$-Loctite, Brasil), no Departamento de Oftalmologia da Santa Casa de São Paulo, entre outubro de 1998 e abril de 2000.

Os parâmetros avaliados foram: idade do paciente, sexo, acuidade visual antes e após aplicação do adesivo (com a correção em uso), medida em milímetros da perfuração ou afinamento, doença ocular que levou diretamente à necessidade da aplicação do adesivo, necessidade de "patch" ou transplante tectônico após tentativa de selar a lesão com a cola, número de aplicações realizadas, tempo de permanência do adesivo, efeitos indesejáveis após a colocação do mesmo e evolução do caso.

Os procedimentos foram realizados ambulatorialmente, com o paciente sentado à lâmpada-de-fenda. Foi instilada uma gota de colírio anestésico (cloridrato de proparacaína $5 \mathrm{mg} / \mathrm{ml}$ ) e o olho mantido aberto com auxílio de blefarostato. Utilizando-se lâmina de bisturi nํ 15 ou cotonete estéril, o tecido necrótico foi retirado e a córnea desepitelizada no local comprometido. Em seguida, secou-se a área com cotonete estéril. $\mathrm{O}$ adesivo de cianoacrilato foi gotejado (3 ou 4 gotas) no interior de uma agulha de calibre 13 X 4,5 ("agulha de insulina"). Uma seringa de $1 \mathrm{ml}$ ("seringa de insulina") foi conectada à agulha. Assim que uma gotícula da cola aparecesse no bisel, esta era aplicada e espalhada sobre a lesão. Aguardou-se cerca de dois minutos para o adesivo secar e em seguida o mesmo foi polimerizado com jato de soro fisiológico ou água destilada estéril. Logo após, uma lente de contato terapêutica hidrofílica foi colocada e foi prescrito colírio de ofloxacina a $0,3 \%\left(\right.$ Oflox $^{\circledR}$ - Allergan Frumtost) na posologia de $6 / 6$ ou $8 / 8$ horas, dependendo do caso. Alguns pacientes continuaram com uso da medicação anterior ao procedimento.

Quando o adesivo caía espontaneamente, a córnea era reexaminada para avaliação da necessidade de aplicação de novo adesivo, "patch" de córnea ou transplante tectônico, ou apenas observação. Em outros casos, quando havia suspeita da resolução da lesão subjacente, o adesivo era retirado no centro cirúrgico, com a mesma reavaliação.

Dos pacientes estudados, $9(41 \%)$ eram do sexo feminino e $13(59 \%)$ do sexo masculino. A média de idade foi de 49,1 anos $+16,9$ (variando de 21 a 78 anos).

RES U L T A D O S

A acuidade visual dos pacientes manteve-se inalterada após a aplicação da cola em 15 casos (68\%), melhorou em 4 (18\%) e piorou em 3 (14\%). Com relação às medidas da área onde a córnea recebeu o adesivo, nenhuma delas ultrapassou 3,2 milímetros de diâmetro; sendo a maioria pertencente ao grupo que variou entre 1 e 2 milímetros (63\%). Dentre as indicações para a aplicação da cola, observou-se que as infecções constituíram a mais freqüente $(50 \%)$, sendo as de etiologia bacteriana seguida das de etiologia herpética as mais comuns. O adesivo foi aplicado em 7 olhos perfurados $(31 \%)$. Doze pacientes $(54 \%)$ não necessitaram de transplante ou "patch" de córnea; já $40 \%$ dos casos necessitaram de um destes procedimentos de emergência, visando à manutenção da integridade ocular. Um paciente teve seu olho eviscerado após evolução desfavorável do quadro clínico inicial. Dos 22 olhos estudados, onze (50\%) receberam apenas uma aplicação do adesivo, oito (36\%) duas e (14\%) três aplicações (Tabela I).

D I S C US S ÃO

As perfurações corneais ou afinamentos graves são situações emergenciais que podem evoluir com infecção e atrofia ocular. Nestas situações, todo esforço deve ser voltado na tentativa de manter a integridade ocular. O tratamento ideal seria aquele que pudesse restabelecer também a integridade funcional ao olho. 


\begin{tabular}{|c|c|c|c|c|c|c|}
\hline $\begin{array}{l}\text { Sexol } \\
\text { Idade }\end{array}$ & $\begin{array}{l}\text { AV antes e após } \\
\text { o uso da cola }\end{array}$ & $\begin{array}{c}\text { Medida } \\
\text { perfur/afinam. }\end{array}$ & $\begin{array}{l}\text { Indicacão } \\
\text { daaplicação }\end{array}$ & $\begin{array}{l}\text { h"ouTP } \\
\text { tônico }\end{array}$ & $\begin{array}{l}\text { Númerode } \\
\text { aplicações }\end{array}$ & $\begin{array}{c}\text { Tempo } \\
\text { depermanência }\end{array}$ \\
\hline F /78 anos & $\begin{array}{l}\text { Antes:MM } \\
\text { Depois:MM }\end{array}$ & $1,0 \times 1,0 \mathrm{~mm}$ & Ceratopatiabolhosa & Não & 1 & 2 meses \\
\hline M/28 anos & $\begin{array}{l}\text { Antes:CD1m } \\
\text { Depois:0,2 }\end{array}$ & $0,8 \times 0,5 \mathrm{~mm}$ & Úlc. bact.perfurada & Não & 2 & $\begin{array}{l}\text { 1a5dias } \\
\text { 2a13dias }\end{array}$ \\
\hline M/32 anos & $\begin{array}{l}\text { Antes:PL } \\
\text { Depois:PL }\end{array}$ & $1,0 \times 3,0 \mathrm{~mm}$ & Úlc.fúngica & $\sin$ & 2 & $\begin{array}{l}1 \div 2 \text { dias } \\
2 \because 5 \text { dias }\end{array}$ \\
\hline M/52 anos & $\begin{array}{l}\text { Antes:MM } \\
\text { Depois:MM }\end{array}$ & $1,0 \times 1,0 \mathrm{~mm}$ & Úlc. bact.perfurada & Não & 1 & 2 e1/2meses \\
\hline F/42 anos & $\begin{array}{l}\text { Antes:CD3m } \\
\text { Depois:CD2m }\end{array}$ & $1,0 \times 1,0 \mathrm{~mm}$ & $\begin{array}{l}\text { Úlc.herpéticae } \\
\text { bacteriana }\end{array}$ & Não & 2 & $\begin{array}{l}\text { 191semana } \\
\text { 2a11meses }\end{array}$ \\
\hline M/58 anos & $\begin{array}{l}\text { Antes:0,4 } \\
\text { Depois:0,4 }\end{array}$ & $2,0 \times 3,0 \mathrm{~mm}$ & $\begin{array}{l}\text { Dellencómeoescleral } \\
\text { pósfacectomia }\end{array}$ & $\sin$ & 3 & 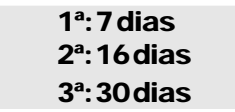 \\
\hline F/59 anos & $\begin{array}{l}\text { Antes: } 1,0 \\
\text { Depois: 1,0 }\end{array}$ & $1,5 \times 1,5 \mathrm{~mm}$ & $\begin{array}{l}\text { Dellen } \\
\text { pósexéresede pterígio }\end{array}$ & Não & 1 & 35dias \\
\hline M/58 anos & $\begin{array}{l}\text { Antes:MM } \\
\text { Depois:MM }\end{array}$ & $2,0 \times 3,0 \mathrm{~mm}$ & Úlc.herpética & Não & 3 & $\begin{array}{l}\text { 1a } 7 \text { dias } \\
\text { 2a6dias } \\
\text { 3a } 23 \text { dias }\end{array}$ \\
\hline F/59 anos & $\begin{array}{l}\text { Antes: MM } \\
\text { Depois:MM }\end{array}$ & $2,0 \times 2,0 \mathrm{~mm}$ & $\begin{array}{l}\text { Úlc.infecciosa } \\
\text { etiol.desconh.perfurada }\end{array}$ & $\sin$ & 2 & $\begin{array}{l}\text { 1a26 dias: } \\
\text { 2a2 e } 1 / 2 \mathrm{~m}\end{array}$ \\
\hline M/44 anos & $\begin{array}{l}\text { Antes: MM } \\
\text { Depois:CD1m }\end{array}$ & $1,3 \times 1,7 \mathrm{~mm}$ & Úlc. bacteriana perfurada & Não & 2 & $\begin{array}{l}\text { 1:20dias } \\
\text { 2:2 meses }\end{array}$ \\
\hline F / 22 anos & $\begin{array}{l}\text { Antes:PL } \\
\text { Depois:PL }\end{array}$ & $0,8 \times 0,8 \mathrm{~mm}$ & Traumaocular & $\sin$ & 1 & Imês \\
\hline M/21 anos & $\begin{array}{l}\text { Antes:MM } \\
\text { Depois:MM }\end{array}$ & $1,0 \times 1,0 \mathrm{~mm}$ & Traumaocular & Não & 1 & 5 meses \\
\hline M/71anos & $\begin{array}{l}\text { Antes:CD3m } \\
\text { Depois:CD3m }\end{array}$ & $2,0 \times 2,0 \mathrm{~mm}$ & Úlcerareumática & $\sin$ & 1 & 1semana \\
\hline M/36anos & $\begin{array}{l}\text { Antes:CD50cm } \\
\text { Depois:CD1m }\end{array}$ & $3,2 \times 1,0 \mathrm{~mm}$ & Traumaocular & $\begin{array}{l}\text { Sim } \\
\text { sceração) }\end{array}$ & 2 & $\begin{array}{l}\text { 1:22dias } \\
\text { 2a } 3 \text { meses }\end{array}$ \\
\hline F/50 anos & $\begin{array}{l}\text { Antes:CD4m } \\
\text { Depois:MM }\end{array}$ & $0,5 \times 0,5 \mathrm{~mm}$ & Fístulapóstransplante & Não & 1 & 1 e $1 / 2$ mês \\
\hline F/67 anos & $\begin{array}{l}\text { Antes:Nula } \\
\text { Depois:Nula }\end{array}$ & $2,5 \times 2,3 \mathrm{~mm}$ & Rejeiçãodetransplante & Não & 1 & 6 meses \\
\hline M / 28 anos & $\begin{array}{l}\text { Antes:MM } \\
\text { Depois:MM }\end{array}$ & $2,0 \times 2,0 \mathrm{~mm}$ & Úlceradeexposição & Não & 2 & $\begin{array}{l}\text { 1a 10 dias } \\
\text { 2a: } 20 \text { dias }\end{array}$ \\
\hline M/65 anos & $\begin{array}{l}\text { Antes:MM } \\
\text { Depois:PL }\end{array}$ & $0,9 \times 1,2 \mathrm{~mm}$ & Úlc.herpética & $\sin$ & 1 & 4dias \\
\hline M/45 anos & $\begin{array}{l}\text { Antes:CD50cm } \\
\text { Depois:CD1m }\end{array}$ & $1,0 \times 1,0 \mathrm{~mm}$ & $\begin{array}{l}\text { Úlc.infecciosa } \\
\text { etiol.desconh. }\end{array}$ & Sim & 3 & $\begin{array}{l}\text { 1‥ } 3 \text { dias } \\
\text { 2a: } 8 \text { dias } \\
\text { 3a: } 14 \text { dias }\end{array}$ \\
\hline F/39 anos & $\begin{array}{l}\text { Antes:MM } \\
\text { Depois:MM }\end{array}$ & $3,0 \times 1,0 \mathrm{~mm}$ & $\begin{array}{l}\text { Afinamentoeperfuração } \\
\text { pósradioterapia }\end{array}$ & Sim & 2 & $\begin{array}{l}\text { 1a } 12 \text { dias } \\
\text { 2a } 5 \text { dias }\end{array}$ \\
\hline M/74 anos & $\begin{array}{l}\text { Antes:MM } \\
\text { Depois:MM }\end{array}$ & $1,2 \times 1,0 \mathrm{~mm}$ & $\begin{array}{l}\text { Úlc.infecciosa } \\
\text { etiol.desconh.perfurada }\end{array}$ & Não & 1 & 24dias \\
\hline F/51 anos & $\begin{array}{l}\text { Antes:MM } \\
\text { Depois:MM }\end{array}$ & $1,0 \times 2,0 \mathrm{~mm}$ & $\begin{array}{l}\text { Úlc.herpéticae } \\
\text { bacterianaperfurada }\end{array}$ & Sim & 1 & 1semana \\
\hline $\begin{array}{l}\text { M=masculino } \\
\text { afinam=afinar } \\
\text { Fonte:Ambula }\end{array}$ & $\begin{array}{l}\operatorname{minino} ; A V=\text { acuidade } \\
\text {;Úlc.=úlcera; bact. =b } \\
\text { leCómeae Moléstias E }\end{array}$ & $\begin{array}{l}\text { Jal (correçãoemu } \\
\text { eriana;etiol.=etio } \\
\text { emas daSantaCas }\end{array}$ & $\begin{array}{l}\mathrm{D}=\text { conta dedos; } \mathrm{MM}=\text { movime } \\
\text {;esconh. =desconhecida } \\
\text { jãoPaulo }\end{array}$ & demão; $F$ & rrcepçãolum & erfur=perfuração; \\
\hline
\end{tabular}

Neste estudo, apenas $18 \%$ dos pacientes apresentaram melhora da acuidade visual (com a correção em uso) após a aplicação da cola. Embora alguns autores tenham relatado índices maiores de melhora da visão ${ }^{(12)}$, nossos dados estão de acordo com outros trabalhos que utilizaram o mesmo adesivo $^{(13)}$. Diversos fatores podem influenciar a acuidade visual final, como localização e etiologia de lesão, precocidade na intervenção, doença de base etc, mas não se pode descartar a toxici- 
dade do adesivo comercial como um dos fatores que influenciou na evolução da cicatrização, já que $14 \%$ dos pacientes evoluíram com piora da acuidade visual após a utilização do adesivo tecidual. Entretanto, a facilidade ao acesso deste tipo de cola em nosso meio, seu baixo custo, a ausência de complicações graves e principalmente pela possibilidade de evitar transplante de urgência, como ocorreu em 54\% dos casos neste estudo, justificam seu uso. A importância disto não está somente relacionada ao fato de evitar os riscos de uma cirurgia de urgência mas também à disponibilidade de tecido biológico (córnea para transplante e "patch").

Não ocorreu injeção inadvertida da cola na câmara anterior e nenhum dos nossos casos evoluiu com formação de simbléfaro.

Um único paciente $(4,5 \%)$ apresentou elevação da pressão intra-ocular após o uso do adesivo, secundária à intensa reação inflamatória intracameral. Neste caso o controle da pressão só foi conseguido com a retirada do adesivo, diferentemente de relato encontrado na literatura ${ }^{(14)}$, onde os autores descrevem 9 complicações descritas com o uso de cianoacrilato; dentre eles, dois casos de aumento da pressão, facilmente controlados com drogas anti-hipertensivas.

As complicações mais comuns encontradas neste estudo foram quemose conjuntival e intensa hiperemia formadas quando o adesivo, ainda no estado líquido, entrava em contato com a conjuntiva. Neste momento, alguns pacientes queixaram-se de dor intensa, dificultando, ou às vezes até impedindo a continuidade da intervenção. Este foi também um fator associado à não aderência da cola, sendo necessário, em alguns casos, uma segunda aplicação. Um dos casos que apresentava afinamento córneo-escleral secundário à cicatrização conjuntival anômala, necessitou, por este motivo, 3 aplicações.

Os autores sugerem que o adesivo seja utilizado em lesões de no máximo 3 milímetros de extensão. Embora alguns autores tenham descrito casos com boa evolução em lesões maiores ${ }^{15}$, quanto maior a área a ser aplicada, maior a quantidade de adesivo necessária, aumentando sua toxicidade ${ }^{(16)}$.

Estudo nacional recentemente publicado ${ }^{(13)}$ encontrou como principal indicação para o uso do adesivo, as úlceras infecciosas. Estas também constituíram a principal indicação neste estudo, mas, diferentemente do primeiro, nesta investigação as infecções bacterianas foram mais freqüentes do que as herpéticas.

No estudo desses mesmos autores ${ }^{(13)}$, realizado em um hospital de referência, $65 \%$ dos olhos que receberam o adesivo estavam perfurados. Valor próximo ao encontrado na instituição onde foi realizado este trabalho (também centro de referência). A adiantada evolução dos casos é um dos motivos responsáveis pelo fato de muitos pacientes evoluírem para cirurgia, podendo parecer que o adesivo não teve sua importância nestes casos. Sabemos que nem sempre tecidos biológicos estão disponíveis numa emergência, mesmo nos grandes hospitais. Observando a tabela de resultados, podese constatar que em muitos pacientes a cola permaneceu por poucos dias. Tempo suficiente para se aguardar a obtenção da córnea doadora ou estabilizarmos clinicamente o paciente, preparando-o para a intervenção cirúrgica.
Embora os pacientes continuem em acompanhamento, percebe-se grande tendência à formação de neovasos em direção ao adesivo que permanece na córnea por vários meses. Aqueles retirados em poucos dias deixam no local da lesão apenas um leucoma não vascularizado. Traumatismos perfurantes não infectados também evoluíram com opacificação discreta quando o adesivo é retirado.

CONCLUS ÃO

Neste estudo, o uso do adesivo tecidual de cianoacrilato mostrou-se método seguro, de fácil realização e de grande utilidade na manutenção da integridade ocular em casos de afinamentos e perfurações corneais, podendo evitar a realização de um transplante tectônico com suas complicações associadas.

A B S T R A C T

Purpose: To report our experience of the use of cyanoacrylate adhesive in 22 cases of corneal perforations and thinning, describing the used technique. Methods: The study consisted of 22 eyes from 22 patients with corneal thinning and perforations from October 1998, to April 2000. All cases were treated with cyanoacrylate adhesive (Super Bonder ${ }^{\circledR}$ - Loctite, Brazil) at the Department of Ophthalmology of the "Santa Casa de São Paulo", Brazil. We evaluated best corrected visual acuity (BCVA) before and after adhesive application, conditions that led to corneal thinning or perforation, measurement of thinning or perforation in millimeters, need for corneal patches or keratoplasty, number of applications, interval in which the adhesive was kept, and adverse reactions. Results: BCVA remained unchanged in $15(68 \%)$ cases. Regarding wound size, $63 \%$ were less than of a $2 \mathrm{~mm}$ diameter and the remaining had a diameter up to $3.2 \mathrm{~mm}$. Infection was the most frequent (50\%) indication for adhesive application. Twelve (54\%) patients did not need surgical procedures to maintain ocular integrity (e.g. patch or keratoplasty). Eleven (50\%) patients received only one application of cyanoacrylate. Conclusion: Application of cyanoacrylate as a tissue adhesive is a safe and easy method. It is very useful in maintaining ocular integrity after corneal perforations and thinning.

Keywords: Cyanoacrylates/utilization; Tissue adhesives/utilization; Corneal transplantation; Cornea/injury

$$
\text { REFERÊNCIAS }
$$

1. Boruchoff SA, Refojo M, Slansky HH, Webster RG, Freeman MI, Dohlman $\mathrm{CH}$. Clinical applications of adhesives in corneal surgery. Trans Am Acad Ophthalmol Otolaryngol 1969;73:499-505.

2. Wendler ME, Lichtenberg W, Falzoni R, Belfort Jr R. Adesivos teciduais no tratamento de perfuração corneana. Estudo comparativo em cobaios. Arq Bras Oftalmol 1983;46:138-40.

3. Refojo MF, Dohlaman CH, Koliopoulos J. Adhesives in ophthalmology: a review. Surv Ophtalmol 1971;15:217-36.

4. Bonati JA, Tolosa EMC, Matheus LCA, Leitão R, Suzuki H, José NK. Cola 
de fibrina em perfuração corneana experimental em cão. Arq Bras Oftalmol 1995;58:88-92.

5. Bonatti JA, Suzuki H, José NK. Tratamento da úlcera corneana perfurada: revisão da literatura. Arq Bras Oftalmol 1997;60:60-6.

6. Eiferman RA, Snyder JW. Antibacterial effect of cyanoacrilate glue. Arch Ophthalmol 1983;101:958-60.

7. Aronson SB, McMaster PR, Moore TE, Coon MA. Toxicity of the cyanoacrylates. Arch Ophthalmol 1970;84:342-9.

8. Gasset AR, Hood CI, Ellison ED, Kaufman HE. Ocular tolerance to cyanoacrylate monomer tissue adhesive analogues. Invest Ophthalmol 1970;9:3-11.

9. Fogle JA,Kenyon KR, Foster CS. Tissue adhesive arrests stromal melting in the human cornea. Am J Ophthamol 1980;89:795-802.

10. Markowitz GD, Orlin SE,Frayer WC, Andrews AP, Prince RB. Corneal endothelial polymerization of histoacryl adhesive: a report of a new intraocular complication. Ophthalmic Surg 1995;26:256-8.

11. Leahey AB, Gottsch JD. Symblepharon associated with cyanoacrylate tissue adhesive. Arch Ophthalmol 1993;111:168.

12. Saini JS, Sharma A, Grewal SP. Chronic corneal perforations. Ophthalmic Surg 1992;23:399-402.

13. Garrido C, Teles D, Koji W, Freitas D. Cola terapêutica de cianocrilato nas perfurações corneanas. Arq Bras Oftalmol 1999;62:683-6.

14. Moschos M, Droutsas D, Boussalis P, Tsioulias G. Clinical experience with cyanocrylate tissue adhesive. Doc Ophthalmol 1996-97;93:237-45.

15. Leahey AB, Gottsch JD, Stark WJ. Clinical experience with N-butyl cyanoacrylate $\left(\mathrm{Nexacryl}^{\circledR}\right)$ tissue adhesive. Ophthalmology 1993;100:173-80.

\section{Curso Inter-americano de Oftalmologia Clínica do Bascom Palmer Eye Institute}

\section{2 a 25 de Novembro de 2.003 Hotel Hyatta Regency - Miami FLORIDA - EUA}

IN FO RMAÇÕES: E-mail: curso@bpei.med.miami.edu Home page: www.bascompalmer.org 